\title{
Low Voltage Capability of Generator for Frequency Regulation of Wind Energy System
}

\author{
Smrutiranjan Nayak ${ }^{1}$, Sanjeeb kumar Kar², Subhransu Sekhar Dash ${ }^{3}$ \\ 1,2 Department of Electrical Engineering ITER, Siksha 'O' Anusandhan University, Bhubaneswar, Odisha, India \\ ${ }^{3}$ Department of Electrical Engineering Government College of Engineering, Keonjhar, Odisha, India
}

\begin{tabular}{|c|c|}
\hline Article Info & ABSTRACT \\
\hline Article history: & For the extraction of wind energy through a doubly fed induction generator \\
\hline Received Oct 17, 2021 & $\begin{array}{l}\text { (DFIG), low voltage is major particular essential controlled by the } \\
\text { transmission structure executive. Under a structure issue condition, DFIG }\end{array}$ \\
\hline Revised Nov 24, 2021 & should remain with respect to the lattice for a particular least period and deal \\
\hline Accepted Dec 20, 2021 & $\begin{array}{l}\text { with open power support on a case-by-case basis by the Transmission } \\
\text { framework administrator. A pleasant control plot involving gear course of }\end{array}$ \\
\hline Keywords: & $\begin{array}{l}\text { action through a superconducting resistance type issue current limiter (R- } \\
\text { SFCL) and programming plan based on the rotor reference current direction }\end{array}$ \\
\hline Wind energy system & control system (RRCOCS) with transient voltage control (TVC) is proposed \\
\hline $\begin{array}{l}\text { Doubly-fed-induction-generator } \\
\text { Low voltage }\end{array}$ & $\begin{array}{l}\text { in this paper to address the Low voltage essential. The results got by the } \\
\text { proposed procedure are differentiated and RRCOCS and RRCOCS-TVC. }\end{array}$ \\
\hline
\end{tabular}

Copyright () 2021 Institute of Advanced Engineering and Science.

Frequency regulation.

Resistive superconducting fault current limiter

All rights reserved.

\section{Corresponding Author:}

Smrutiranjan Nayak,

Department of Electrical Engineering,

Department of Electrical Engineering ITER, Siksha 'O' Anusandhan University

Bhubaneswar, Odisha, India

Email: smrutikiit40@gmail.com

\section{INTRODUCTION}

The doubly-fed induction generator (DFIG) has been broadly utilized in the breeze energy framework because of its variable working rate range, lower rating of converters, and adaptability in genuine force and receptive force control. In DFIG, the stator is straightforwardly associated with the lattice, and the force move from the stator to the network is controlled using the rotor side converter (RSC). The grid side converter (GSC) controls the voltage of the dc transport introduced between the force electronic converters. It is liable for directing the dynamic and responsive force move between the framework and the rotor of DFIG [1]. Because of the increased entrance of wind-based force age in the electric utility framework, wind energy system (WES) is should have been explored for the network issue condition.

The DFIG's stator direct association with the lattice is a major worry for the force makers and utility framework during matrix shortcoming [2]. The voltage level at the lattice association point gets diminished during network blames and results in a high transient stator current. This likewise detrimentally affects the rotor, since it is attractively coupled to the stator, and adds to the progression of huge current in the rotor [35]. The rotor emf additionally increments and crosses the greatest reasonable worth under lattice shortcomings $[6,7]$. The high measure of the rotor circuit current and expanded rotor emf of DFIG are liable for the RSC disappointment and the dc-connect voltage destabilization. Because of the disappointment of RSC, there is a finished loss of control of DFIG. The undermined DC-connect voltage diminishes the capacitor life and furthermore turns down the proficiency of force converters. In addition, the gearbox and direction additionally face high mechanical pressure because of force motions and may deteriorate their life expectancy [8]. WES is compelled to satisfy a particular specialized prerequisite as far as matrix codes for the transmission 
organization's continuous commitment. Such framework codes are indicated by the transmission system operator (TSO). Fault ride-through (FRT) is the capacity of the force framework organization to support the issue occasions fulfilling the laws forced by the utility lattice. Low voltage is one of the imperative framework code necessities in which WES should remain coupled to the matrix even in the episode of the issue for a particular least time and shield WES from electrical and mechanical irregularities [9].

Methods proposed in the available literature to enhance the Low voltage performance of DFIG-WES can be summarized as i) software control improvement through RSC of DFIG and (ii) modified hardwarebased solutions. Software solutions proposed in the literature are based on the modification in RSC's control structure either with a new controller topology or with some transient modified algorithms. Several schemes are proposed in the literature without modifying the reference current of the conventional control structure. A genetic algorithm-based optimally tuned LQR controller is proposed with an improved dynamic response when compared to a PI controller [10]. The controller performance was found robust to perturbation in stator voltage. Similarly, the authors have proposed a nonlinear sliding mode theory application in improving the LVRT of a DFIG- WECS [11]. The controller's performance was robust to perturbation in wind speed and machine parameters and proved to enhance the LVRT ability during faults. Employment of a model predictive control (MPC) scheme has proved in improving the damping, accuracy, and speed of the controller to track reference currents during fault [12]. These methods can improvise the performance of the control system but do not escape the need for enough voltage by the RSC to offset the rotor emf. Software methods with modified reference current include a demagnetizing control designed to counteract the natural and negative components associated with transient flux [13]. A flux linkage control is realized to suppress overcurrent in the rotor circuit by regulating the flux produced in the rotor to trace the proportionate flux in the rotor [14]. RSC of DFIG emulates the characteristics of inductance and is proved in improving ride-through capability [15]. A rotor reference current orientation control strategy (RRCOCS) is proposed in which the current reference is modified for the rotor current loop by following an orientation scheme with the stator circuit current to overturn the rotor circuit high current and reduce the rotor emf [16]. However, the RSC-based performances' performances are limited to moderate voltage dips, and they underperform during severe grid fault scenarios. The rotor current's peak goes far beyond the permitted level and, the rotor terminal voltage requirement significantly reaches a fairly high value. Hence, RSC may not have the capability to introduce any reactive power control. Due to extremely low voltage at the common coupling point (PCC) under such a severe fault condition, the reactive power DFIG available to DFIG is not sufficient to support the voltage at the PCC. It is unable to carry out the control of reactive power in its entirety [17]. The crowbar circuit is the most common hardware modification method applied when the current in the rotor circuit exceeds the permissible level [18]. The crowbar circuit is simple in design and is a low-cost device. However, DFIG with a crowbar circuit is similar to the caged induction generator (SCIG) and draws reactive power from the grid. Dynamic braking resistor (DBR) in series is another cost-efficient approach for LVRT improvement of large wind farms. Static compensator (STATCOM) dynamic voltage stabilizer (DVS), gate-controlled series capacitor (GCSC) is some other proposed auxiliary hardware methods. These methods help achieve better transient performance and compensate for the reduced PCC voltage. A bridge-type fault current limiter is proposed where the faulty current passes through a dc reactor and dissipates resistance and is proved in improving LVRT dynamics [19]. Another article has presented a fault current limiter with the capacitive bridge (CBFCL) for LVRT improvement. It has got improved merits over BFCL in terms of reactive power support, reduced complexity in the circuit, and reduced cost. Hybrid hardware solutions are also proposed to give improved results [20-21]. However, the deployment of additional converters, transformers, and circuit components makes them an expensive choice and increases the system's complexity. Also, reactive power available with the converters is limited to upkeep the PCC voltage under severe grid faults. With some hardware modifications in the reactors of fault current limiters, it behaves like a high-temperature superconductor (HTS). Superconducting resistance fault current limiter (R-SFCL) with features of quick response, self-triggering, and self-recovery has been proved effective in enhancing the LVRT ability of DFIG-WECS by restraining the fault current. Several SFCL schemes have been suggested in the literature [22]. SFCL cannot deliver adequate reactive power support to sustain higher grid voltage support. However, selecting a higher value for the current limiting resistance of SFCL can further improve the PCC voltage but it will also produce a significant amount of joule heating within the SFCL and increase the post fault recovery time. This could result in overcompensation of the stator voltage and significantly high electromagnetic transients [23-25]. Also, excessive Joule heating can even damage RSFCL and its superconducting property with a repeated number of operations. On the other hand, the SFCL installed on the grid-tied lines cannot individually meet the limiting capacity for the rotor current of each DFIG in a wind farm. Taking into account the prevailing limitations in the LVRT control approaches of R-SFCL hardware device alone and RSC-based control alone, this article proposes a cooperative control technique merging with a hardware device and modified software scheme.

IJEEI, Vol. 9, No. 4, December 2021: 983 - 992 
In this paper, a resistance-type SFCL is utilized to enhance the terminal voltage of DFIG in the event of grid side faults, and improved RSC control methods (RRCOCS) and the transient voltage control (TVC) using GSC and RSC is introduced to perk up the transient performance. The proposed scheme can limit the rotor circuit over current, suppress the electromagnetic torque oscillations, and ensure that the terminal voltage at the PCC is sustained as per utility grid codes. The smoother electromagnetic torque achieved through the proposed scheme reduces the machine-driven stress on the wind turbines (WT). Moreover, the requirement of R-SFCL current limiting resistance is significantly reduced with the proposed scheme which enhances the recovery characteristics and reduces the thermal stress of SFCL[26-28].

\section{MATERIALS AND METHODS}

DFIG-WES consists of a wind-driven turbine with its control unit, the wound rotor induction generator, and a set of two adjacent pulse width modulated (PWM) power electronic converters with its control structure. The generator is coupled to the grid using a step-up transformer as per the grid voltage level as shown in Fig. 1. The WECS control entails the turbine control and the converter control at two levels. Wind turbine control is performed first to determine the generator reference torque and pitch angle reference to meet several requirements; i.e., to extract maximum available energy from wind by MPPT, keep turbine within safe operational limits in terms of (power, speed, and torque) [1]. Converter control at the second level is used to generate the switching pattern of GSC and RSC using the reference generated by wind turbine control [1]. The converter control is based on traditional vector control applied on RSC and GSC. The control strategy at twolevel is therefore used for the optimization of power in the safe wind speed range. Also, it helps limit power production for abnormal wind speeds. Mathematical model development of DFIG is required for the realization of two-level control strategies which is presented in the subsequent section.

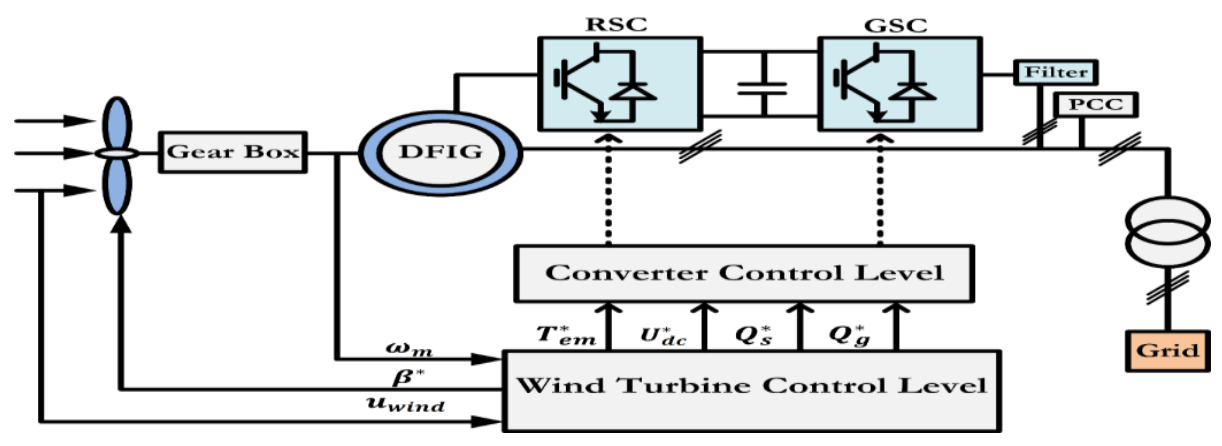

Figure 1. Schematic diagram of DFIG

\subsection{DFIG MATHEMATICAL MODEL}

Using the most common park model for induction generator, the stator and the rotor winding voltage vectors of DFIG in stationary reference frame can be expressed as [2]:

$$
\begin{aligned}
& \vec{u}_{s}=R_{s} \vec{i}_{s}+\frac{\partial \vec{\psi}_{s}}{\partial t} \\
& \vec{u}_{r}=R_{r} \vec{i}_{r}+\frac{\partial \vec{\psi}_{r}}{\partial t}-j \omega_{r} \vec{\psi}_{r}
\end{aligned}
$$

where $\vec{u}_{s}, R_{s}$ and $\vec{\psi}_{s}$ are stator voltage vector, stator resistance, and stator flux linkage vector, respectively. Similarly, $\vec{u}_{r} R_{r}$ and $\vec{\psi}_{r}$ are rotor voltage vector, rotor resistance, and rotor flux linkage vector, respectively. The rotor speed is symbolically represented by $\omega_{r}$.

The grid determines the stator voltage $\vec{u}_{s}$ as the stator is directly connected with the grid. PWM converter controls the rotor voltage to perform the desired power or torque control. The developed flux linkages around the stator and rotor windings of DFIG are given by:

$$
\begin{aligned}
& \vec{\psi}_{s}=L_{s} \vec{i}_{s}+L_{m} \vec{i}_{r} \\
& \vec{\psi}_{r}=L_{r} \vec{i}_{r}+L_{m} \vec{i}_{s}
\end{aligned}
$$

where $L_{s} L_{r}$, and $L_{m}$ are the stator circuit self-inductance, rotor circuit self-inductance, and mutual inductance between stator and rotor circuits, respectively. 
The generator torque in synchronous $(\mathrm{d}-\mathrm{q})$ reference frame can be expressed as[1]:

$T_{e m}=p \frac{L_{m}}{L_{s}} \operatorname{Im}\left(\vec{\psi}_{s d q} \vec{i}_{r d q}^{*}\right)=p\left(\vec{\psi}_{s q} \vec{i}_{r d}-\vec{\psi}_{s d} \vec{i}_{r q}\right)$

where $p$ symbolizes the numerical value of poles in pairs.

Applying fundamental dynamic law on the generator's rotating part, rotor speed $\left(\omega_{r}\right)$ of the DFIG can be evaluated as:

$$
J_{g e n} \frac{d \omega_{r}}{d t}=T_{m}-T_{e m}
$$

where $J_{\text {gen }}$ represents the inertia equivalent of the machine; $T_{e m}$ and $T_{m}$ symbolizes electromagnetic torque and mechanical torque, respectively.

\subsection{VECTOR CONTROL OF DFIG}

In the classical vector control approach of the DFIG, the power electronics converter is being controlled by the traditional PI controller using d-q transformation. The control strategy for the converters, RSC, and the GSC are presented in Fig. 2. RSC control is centered on the stator-voltage-oriented form of the vector control. The in effect decouple control is accomplished round the reasonably autonomous d-axis and qaxis controller loops using conventional PI controllers. This is realized by the alignment of the d-axis of the (d-q) frame of reference with the DFIG's stator voltage vector.

The generator torque and the reactive power flow in the stator can then be expressed as:

$$
\begin{aligned}
& T_{e m}=\frac{L_{m}}{L_{s}} \psi_{s q} i_{r d} \\
& Q_{s}=\omega_{s} \frac{L_{m}}{L_{s}} \psi_{s q} i_{r q}-\omega_{s} \frac{\psi_{s q}}{L_{s}} \psi_{s q}
\end{aligned}
$$

where $\omega_{s}$ as the synchronous frequency of the DFIG stator variables.

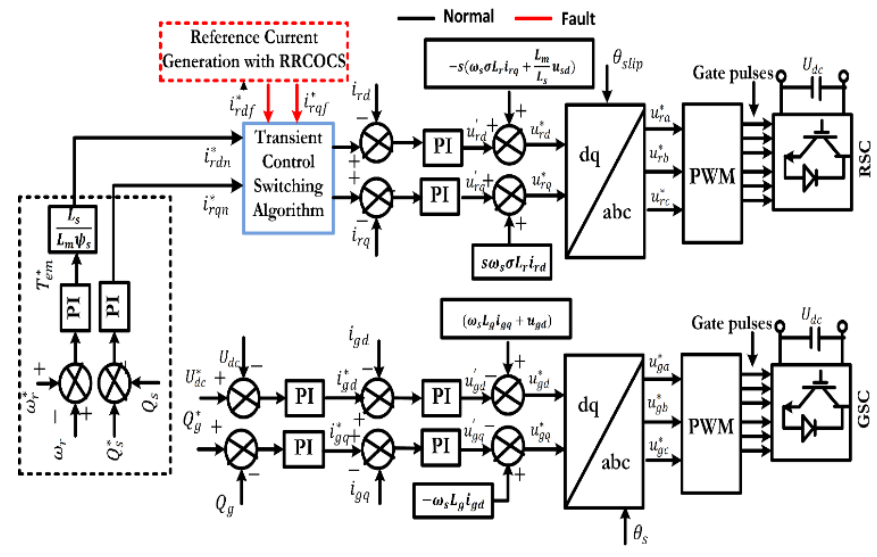

Figure 2. RSC and GSC control diagram.

The generator torque and reactive power through the stator are directly proportional to $\mathrm{d}$ - and q-axis current in the rotor, respectively. The DC-link voltage $\left(U_{d c}\right)$ is being regulated by GSC control regardless of the mode of operation of DFIG, i.e.; subsynchronous and super synchronous. Similar to the control structure of RSC, GSC control is realized by the orientation of the $d$ - axis of the $(\mathrm{d}-\mathrm{q})$ frame of reference with the utility grid voltage vector. The voltage at the dc bus is proportional to $\left(i_{g d}\right)$ i.e., the d-axis current amid grid and GSC. While the reactive power flowing amid GSC and the grid is relative to the q-axis current $\left(i_{g q}\right)$. The currents $i_{g d}$ a $i_{g q}$ re regulated by controlling d-axis voltage $\left(u_{g d}\right)$ and q-axis voltage $\left(u_{g q}\right)$, respectively. The $\mathrm{d}$-axis reference current $\left(i_{g d}^{*}\right)$ is generated employing a PI regulator loop around the voltage at the dc-link. Likewise, the q-axis reference current $\left(i_{g q}^{*}\right)$ is obtained from the controller loop over reactive power flowing 
through GSC is shown in Fig. 2. It is generally preferred for DFIG to operate at unity power factor in normal conditions to minimize losses and exploit the active power transmission. Hence, the reference reactive power for both converters' control is tuned to zero.

The conventional Vector control performs well under normal operation. However, to protect the WECS and to improve the system's transient performance during fault events, it is required to introduce a modified control structure and circuits. Several modified software control schemes and hardware methods have been evolved by the power system researcher. Cooperative hardware and modified software transient control scheme are purported in this paper for improving the performance during the fault.

\subsection{COOPERATIVE CONTROL TOPOLOGY \& PRINCIPLE}

The schematic representation of the proposed cooperative control with a resistance type SFCL and two improved converter control methods of DFIG is shown in Figure 3. The wind farm system includes 6 wind turbines, each of 1.5 MW DFIGs connected to the grid. The SFCL is installed in between the DFIG terminal (bus 1) and the (transformer1). The equivalent grid fault analysis model for the entire system under a test condition of the most severe three phases with ground fault is represented in Figure 4.

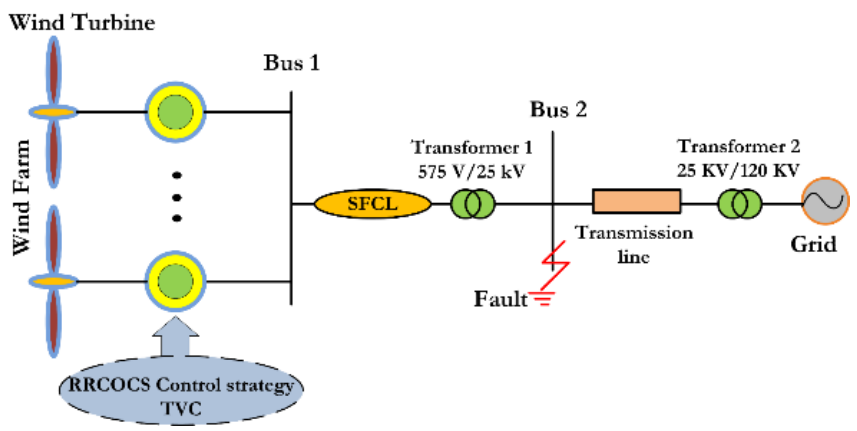

Figure 3. Schematic of the proposed cooperative control topology.

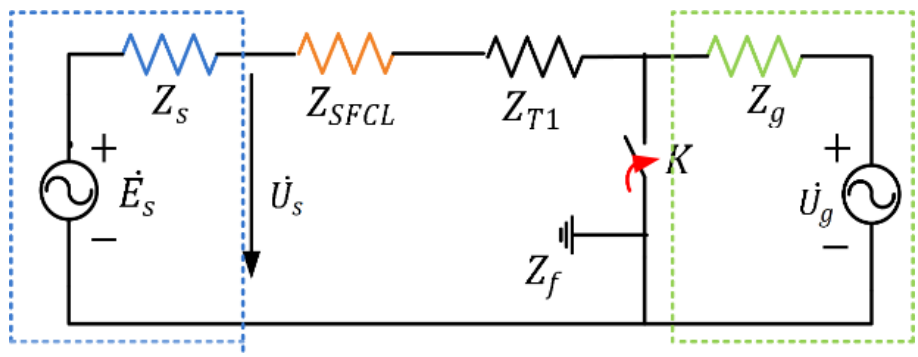

Figure 4. Equivalent fault analysis model of the test system under grid fault.

With the drop in voltage at Bus 1, the three-phase to ground fault also roots a severe current flow through stator winding. The moment the stator winding current surpasses the critical current level of the SFCL tied in line, a self-operating SFCL starts quenching and increases its impedance to a sudden high value, and develops a fairly high voltage potential across the SFCL. Meanwhile, the RRCOCS and TVC control are exploited to protect the DFIG from over current and contribute reactive power to support the grid voltage, respectively.

\subsection{R-SFCL EQUIVALENT MODELING}

R- SFCL can be represented by a time-varying resistance whose characteristics can be depicted in Figure 5. Under normal operation of the grid up to time $t_{1}$, the SFCL offers zero resistance since the SFCL current is within the critical current limit. For the grid fault occurring at the time $t_{1}$, the overcurrent starts the quenching process and the SFCL finally reaches a state with high resistance at the time $t_{2}$. 


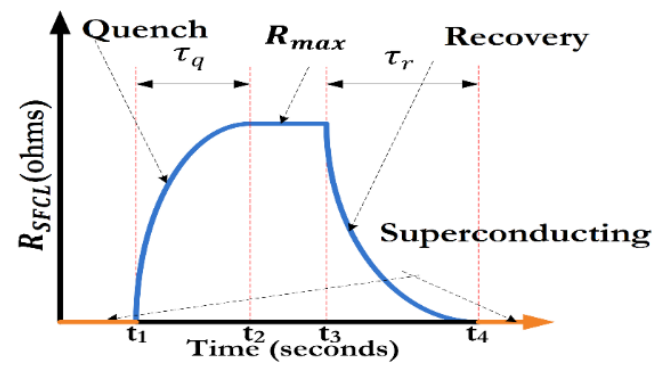

Figure 5. Resistance characteristics curve of SFCL.

After the grid fault disappearance at the time $t_{3}$, the SFCL comes back to the original superconducting state at the time $t_{4}$. The SFCL's resistance under different operating states can be expressed mathematically as:

$$
R_{S F C L}= \begin{cases}R_{\max } \times\left[1-\exp \left(-t / \tau_{q}\right)\right] & t_{1}<t<t_{2} \\ R_{\max } & t_{2}<t<t_{3} \\ R_{\max } \times\left[\exp \left(-t / \tau_{r}\right)\right] & t_{3}<t<t_{4}\end{cases}
$$

where $R_{\max }$ is the maximum resistance offered by SFCL after completing the quenching process. $\tau_{q}$ and $\tau_{r}$ symbolizes the time constant of the quenching process and recovery process, respectively.

The triggering and state transition of SFCL is modeled in MATLAB power systems. The voltage variation across SFCL owing to an instantaneous change in its resistance is imitated by a controlled voltage source dependent on fault current. This voltage is then inserted into the grid-connected line and mimics the fault current limiting effect of the SFCL.

\section{MODIFIED CONTROL SCHEME FOR DFIG CONVERTERS}

The use of SFCL based hardware method is coordinated with two modified control schemes for converters, TVC, and RRCOCS to improve the inclusive transient performance of WECS and bring improvement in terms of cost-saving and reduction in energy losses associated with the SFCL device.

\subsection{TRANSIENT VOLTAGE CONTROL (TVC)}

To integrate the participation of RSC and GSC for transient voltage improvement, a modified control scheme is developed by the power system researcher and presented in Figure 6. The objective of the control is to achieve reactive power support through RSC only till its maximum power limit. Beyond the maximum power limit of RSC, GSC starts sharing the reactive power. Under the normal operating condition, the reactive power references are set to zero. During faults, the reference reactive power is yielded by regulating the error voltage between the reference stator voltage and the actual stator voltage over a PI controller. Due to the slow response time of RSC as compared to GSC, the reactive power reference is preferentially given to the RSC control. I.e., it firstly uses the RSC for reactive power generation, and when the current becomes seriously high the remainder of the net reactive power is fed as a reference to the GSC.

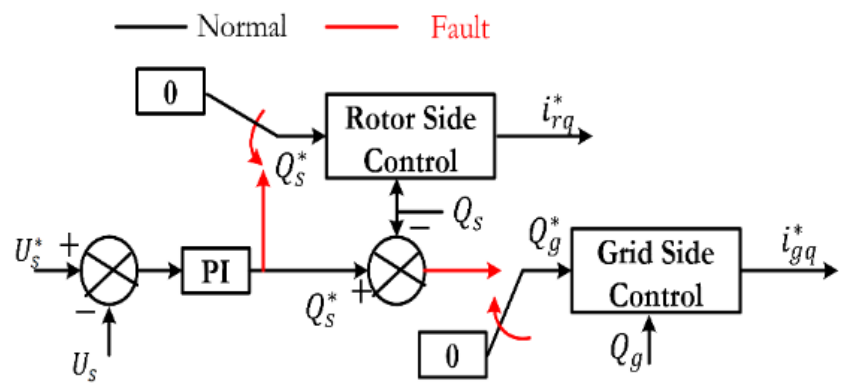

Figure 6. Converters control diagram with TVC capability 


\subsection{RRCOCS CONTROL STRATGY}

In this paper, the RRCOCS control strategy is employed to reduce the rotor over-current and rotor emf during grid fault. In this software-based scheme, the reference rotor current gets oriented with the stator current during fault episode. In the occurrence of a fault, the stator of DFIG experiences a dip in voltage level. The flux being a state variable, cannot experience any discontinuity. The stator flux does not change to a new steady-state value at a sudden and evolves with a transient component known as natural flux along with the ac component called forced flux. Hence, the flux value at the instant of fault gets a sudden rise due to the presence of two components and slowly settles down to a new steady-state value.

The DFIG stator voltage and flux post voltage dip can be expressed as :

$$
\begin{aligned}
& \vec{u}_{s}=U_{s 2} e^{j \omega_{s} t} \\
& \vec{\psi}_{s}(t)=\frac{U_{s 2}}{j \omega_{s}} e^{j \omega_{s} t}+\frac{U_{s 1}-U_{s 2}}{j \omega_{s}} e^{-t / \tau_{s t}}
\end{aligned}
$$

where $U_{s 1}$ and $U_{s 2}$ represents pre-fault and post-fault amplitude of stator voltage, $\omega_{s}$ is the speed at which the stator voltage space vector rotates, and $\tau_{s t}=L_{s} / L_{r}$ is the stator time constant of DFIG. It is also proved from the article that the rotor current orientation further improves the transient voltage rise associated with rotor emf and DC-link voltage.

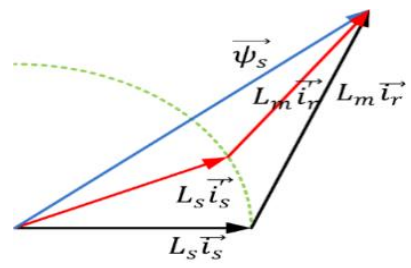

Figure 7. Phasor representation between stator-flux, stator circuit current, and rotor current.

\section{RESULTS \& DISCUSSIONS}

The proposed control strategy is tested on the system and represented in Figure 3. The performance of the proposed cooperative LVRT method is evaluated under a three-phase symmetric fault condition with a grid voltage sag level of 0.99 at $t=0.835 \mathrm{~s}$ which lasts for 100 milliseconds. The symmetric three-phase to a ground fault has been considered in this paper for the performance evaluation due to its maximum severity. Three test conditions based on different control strategies have been investigated in this paper for the performance comparison, namely, Case A: only with RRCOCS; Case B: with RRCOCS and TVC; and the proposed test Case C: with R-SFCL, RRCOCS, and TVC. The pre-set resistance value of R-SFCL is chosen as 8 milliohms for the proposed test case $\mathrm{C}$.

The electromagnetic torque behavior for a three-phase symmetric fault is presented in Figure 8. The peak value of the electromagnetic torque reaches ( 2.3 p.u.) and ( 2.4 p.u.) for case A and case B, respectively. However, it is limited to1.8 p.u. with the proposed control strategy termed as Case and is below the maximum permitted value (2.0 p.u.). Also, the oscillations in electromagnetic torque get smoother in Case C, compared to Case A and Case B. This can prevent the mechanical system from vibrations, reduce the mechanical stress on them, and increase their life span.

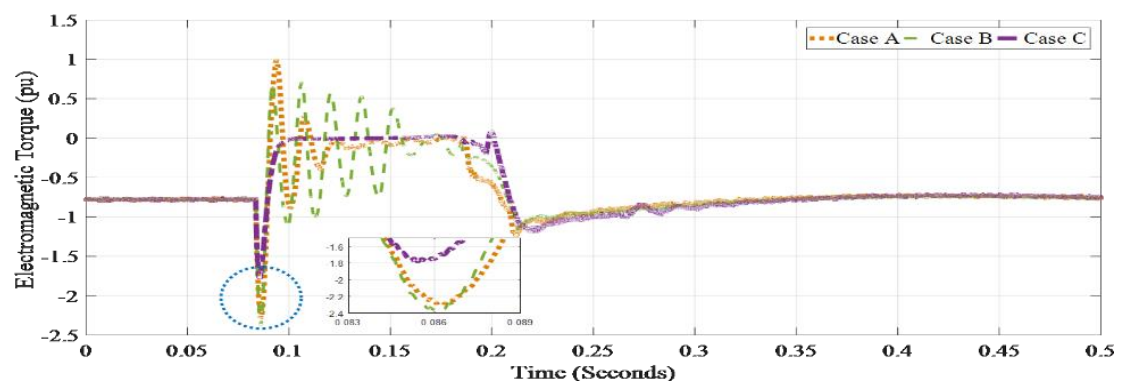

Figure 8. Electromagnetic Torque response for DFIG. 


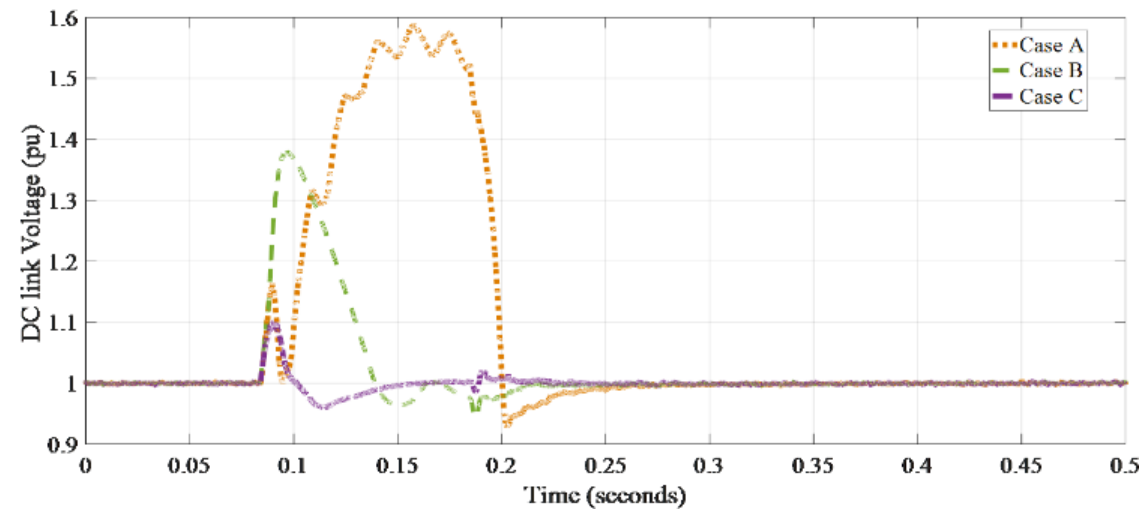

Figure 9. DC bus voltage response for DFIG.

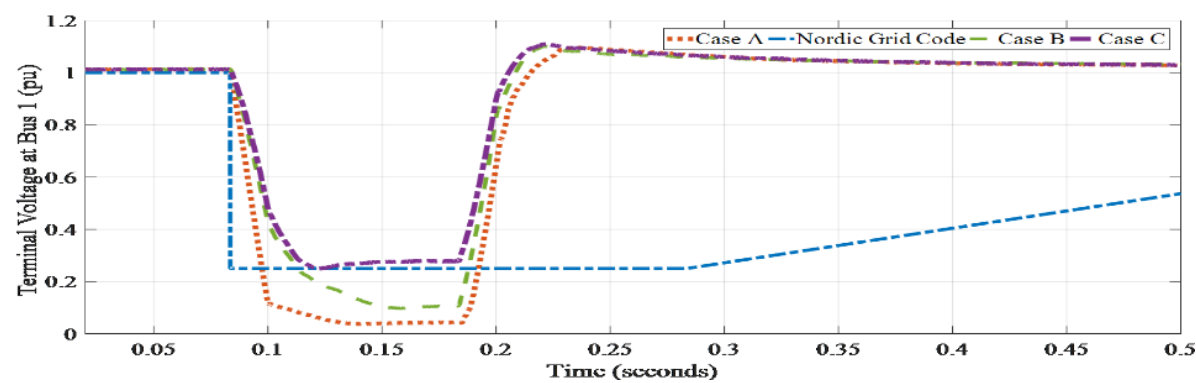

Figure 10. The terminal voltage at bus 1 is under a three-phase fault.

The response of DC-link voltage has been shown in Figure 9. With RRCOCS in Case A, the dc bus voltage peak goes to 1.59 p.u., surpassing the permissible safe limit (1.2 p.u.). Through the addition of TVC in Case B, excess energy available with the dc bus capacitor can be used for reactive power generation through RSC and GSC. And hence the dc-link voltage peak reduces to 1.38 p.u. However, with the deployment of SFCL in Case C, the dc bus voltage peak is further restricted to 1.1 p.u.

Figure 10 reveals that with the RRCOCS only, the DFIG experiences a low terminal voltage close to 0.04 p.u. during the fault duration. In Case B, the TVC contributes to reactive power injection by DFIG converters, and the terminal voltage gets improved to 0.09 p.u. When the SFCL, TVC, and RRCOCS are applied cooperatively in Case $\mathrm{C}$, the minimum voltage at the terminal is enhanced to $0.26 \mathrm{p}$.u. fulfilling the Nordic grid requirements. Also, the R-SFCL resistance requirement in test case $\mathrm{C}$ is just 8 milliohms compared to 16 milliohms required for an independent R-SFCL to achieve a similar terminal voltage improvement.

Figure 11-13 shows the responses of rotor current among the three cases. The RRCOCS scheme has limited ability to perk up the ride-through performance of DFIG amid a deep voltage sag. The rotor peak current values in Case A and Case B can only be restricted to 4.07 p.u. and 4.15 p.u., respectively. These current levels are beyond the permissible value (2.0 p.u.). In Case C, the SFCL supports to improve the wind farm voltage at the terminal, hence the rotor current peak value is further suppressed to 1.9 p.u.

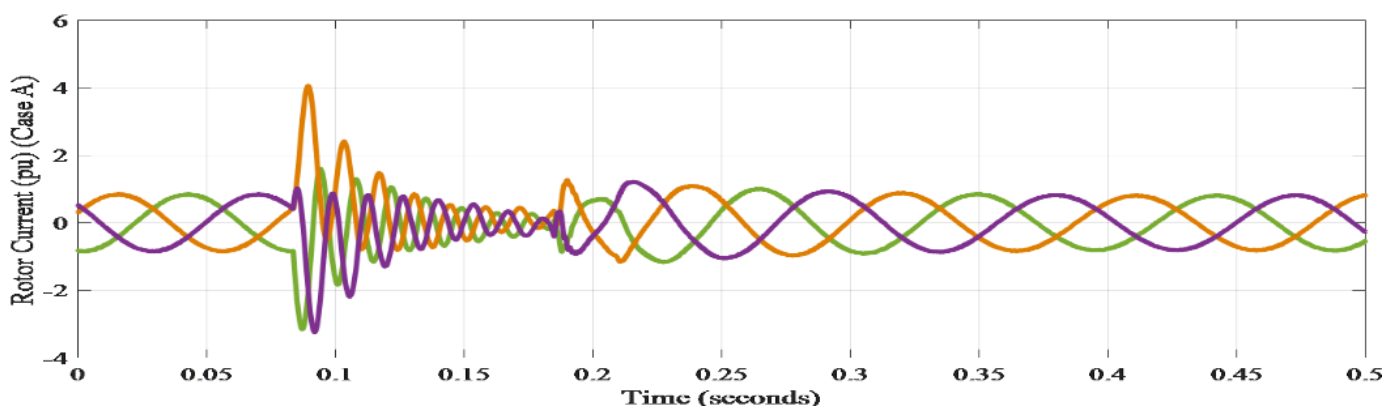

Figure 11. DFIG rotor winding currents (Case A). 


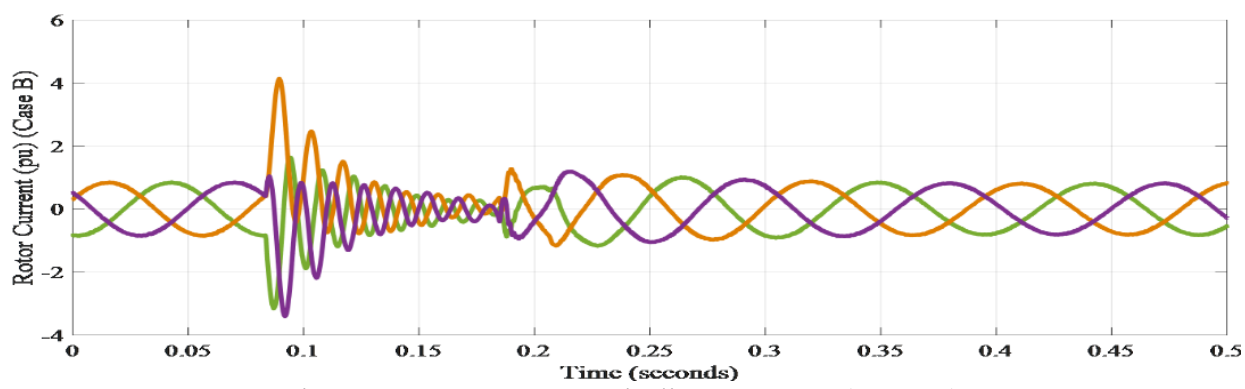

Figure 12. DFIG rotor winding currents (Case B).

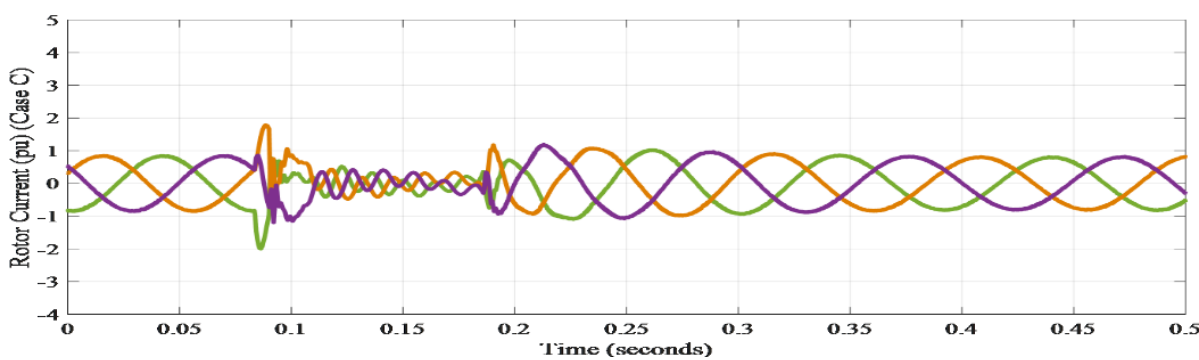

Figure 13. DFIG rotor winding currents (Case C).

\section{CONCLUSION}

A new cooperative scheme merging the hardware circuit and software solution has been proposed in this paper for maintaining the LVRT requirement. In this cooperative scheme, the hardware solution is implemented using R-SFCL and the software solution through RRCOCS-TVC. The cooperative control strategy is being tested on the system given in Figure 3. From the test result, the effectiveness of the proposed method is established in terms of the electromagnetic torque, rotor current, and dc bus voltage under severe fault conditions. Also, the voltage at the wind generator bus terminal is improved to satisfactorily meet the specified utility grid code at a reduced rating of R-SFCL resistance. This further improves the thermal performance of SFCL and enhances its recovery characteristics.

\section{REFERENCES}

[1] S Müller, M Deicke and RW De Doncker, “ Doubly fed induction generator systems for wind turbines ",IEEE Ind. Appl. Mag. 2002; 8, 26-33.

[2] J López, E Gubía, P Sanchis, X Roboam, and L Marroyo,“ Wind turbines based on doubly fed induction generator under asymmetrical voltage dips. IEEE Trans. Energy Convers", 2008; 23, 321-330.

[3] SQ Bu, W Du, HF Wang and S Gao. Power angle control of grid-connected doubly fed induction generator wind turbines for fault ride-through. IET Renew. Power Generate. 2013; 7, 18-27.

[4] FKA Lima, A Luna, P Rodriguez, EH Watanabe, and F Blaabjerg," Rotor voltage dynamics in the doubly-fed induction generator during grid faults. IEEE Trans Power Electron,” 2010; 25, 118-30.

[5] Z Din, J Zhang, Y Zhu, Z Xu, and A El-Naggar, "Impact of grid impedance on LVRT Performance of DFIG system with rotor crowbar technology", IEEE Access. 2019; 7, 127999-8008.

[6] J Hu, Y Huang, D Wang, H Yuan, and X Yuan, "Modeling of grid-connected DFIG-based wind turbines for dc-link voltage stability analysis. IEEE Trans. Sustain. Energy,” 2015; 6, 1325-36.

[7] M Tsili and S Papathanassiou. A review of grid code technical requirements for wind farms. IET Renew. Power Generate. 2009; 3, 308-32.

[8] R Bhushan and K Chatterjee, "Mathematical modeling and control of DFIG-based wind energy system by using optimized linear quadratic regulator weight matrices," Int Trans. Electr. Energy Syst. 2017, DOI: 10.1002/etep.2416.

[9] S Li, J Huang and T Sun," Analytical LVRT analysis of doubly fed induction generator with MPC-based DSCC/DRCC,” IET Renew. Power Generate. 2019; 13, 2462-71.

[10] L Zhou, J Liu, and S Zhou,“ Improved Demagnetization Control of a Doubly-Fed Induction Generator under Balanced Grid Fault," IEEE Trans Power Electron. 2015; 30, 6695-705.

[11] S Xiao, G Yang, H Zhou, and H Geng, “ An LVRT control strategy based on flux linkage tracking for DFIG-based WECS," IEEE Trans. Ind. Electron. 2013; 60, 2820-32.

[12] D Zhu, X Zou, L Deng, Q Huang, S Zhou, and Y Kang, "Inductance-Emulating Control for DFIG-Based Wind Turbine to Ride-Through Grid Faults, "IEEE Trans. Power Electron. 2017; 32, 8514-25.

[13] W Teng and Y Meng. Rotor-reference-current-oriented control strategy for low-voltage ride-through of DFIG. IEEJ Trans. Electr. Electron. Eng. 2018, DOI: 10.1002/tee.22708. 
[14] D Xie, Z Xu, L Yang, J Ostergaard, Y Xue, and KP Wong,“ A Comprehensive LVRT Control Strategy for DFIG Wind Turbines with Enhanced Reactive Power Support”, IEEE Trans. Power Syst. 2013; 28, 3302-10.

[15] KE Okedu, SM Muyeen, R Takahashi and J Tamura., "Wind farms fault ride through using DFIG with new protection scheme", IEEE Trans. Sustain. Energy. 2012; 3, 242-54.

[16] W Qiao, R Harley, and G Venayagamoorthy. Coordinated reactive power control of a large wind farm and a STATCOM using heuristic dynamic programming. In: Proceedings of the 2009 IEEE Power Energy Soc. Gen. Meet, Calgary, AB, Canada, 2009.

[17] C Wessels, F Gebhardt, and FW Fuchs, “Fault ride-through of a DFIG wind turbine using a dynamic voltage restorer during symmetrical and asymmetrical grid faults", IEEE Trans. Power Electron. 2011; 26, 807-15.

[18] H Mohammadpour, SG Zadeh and S Tohidi, "Symmetrical and asymmetrical low-voltage ride-through of doublyfed induction generator wind turbines using gate-controlled series capacitor”, IET Renew. Power Generate. 2015; 9 , $840-6$.

[19] M Firouzi. A modified capacitive bridge-type fault current limiter (CBFCL) for LVRT performance enhancement of wind power plants. Int Trans. Electr. Energy Syst. 2018, DOI: 10.1002/etep.2505.

[20] W Uddin, K Zeb, A Tanoli and A Haider , "Hardware-based hybrid scheme to improve the fault ride-through capability of doubly fed induction generator under symmetrical and asymmetrical fault ", IET Gener. Transm. Distrib. 2018; 12, 200-6.

[21] X Xiao, R Yang, X Chen, Z Zheng and C Li,"Enhancing fault ride-through capability of DFIG with modified SMESFCL and RSC control", IET Gener. Transm. Distrib. 2018; 12, 258-66.

[22] ZC Zou, XY Xiao, YF Liu, Y Zhang, and YH Wang, “Integrated Protection of DFIG-Based Wind Turbine with a Resistive-Type SFCL under Symmetrical and Asymmetrical Faults", IEEE Trans. Appl. Supercond. 2016; $26,1-5$.

[23] R Ou, XY Xiao, ZC Zou, Y Zhang, and YH Wang, "Cooperative Control of SFCL and Reactive Power for Improving the Transient Voltage Stability of Grid-Connected Wind Farm with DFIGs," IEEE Trans. Appl. Supercond. 2016; 26, $1-6$.

[24] K.S.Rajesh, and S.S.Dash, "Load frequency control of the autonomous-power system using adaptive fuzzy based PID controller optimized on improved sine cosine algorithm, "Journal of Ambient Intelligence and Humanized Computing, vol. 10, pp. 2361-2373, 2019.

[25] D.Khamari, and R.K.Sahu, "A modified moth swarm-algorithm based hybrid fuzzy PD-PI controller for frequency regulation of distributed power generation system with an electric vehicle," J Control Autom Electr Syst,DOI: 10.1007/s40313-020-00565-0,2020.

[26] K. Nouman, Z. Asim, and K. Qasim, "Comprehensive Study on Performance of PID Controller and its Applications," In 2018 2nd IEEE Advanced Information Management, Communicates, Electronic and Automation Control Conference (IMCEC), pp. 1574-1579, IEEE, 2018, doi: 10.1109/IMCEC.2018.8469267.

[27] Z. A. Hamid, S. Jipinus, I. Musirin, M. M. Othman, and R. H. Salimin., "Optimal sizing of distributed generation using firefly algorithm and loss sensitivity forVoltage stability improvement," Indonesian. J. Elec. Eng. \& Comp. Sci., vol. 17, no. 2, pp. 720-727, 2020, doi: 10.11591/ijeecs. v17.i2. pp720-727.

[28] T. S. Gorripotu, R. K. Sahu, and S. Panda, "Comparative performance analysis of classical controllers in LFC using FA technique", IEEE International Conference on Electrical, Electronics, Signals, Communication Optimization (EESCO), 2015, pp. 1-5, doi: 10.1109/EESCO.2015.7254014. 